This item was submitted to Loughborough's Research Repository by the author.

Items in Figshare are protected by copyright, with all rights reserved, unless otherwise indicated.

From local project to open source: a brief history of the Loughborough Online Reading List System (LORLS)

PLEASE CITE THE PUBLISHED VERSION

PUBLISHER

(C) Emerald

LICENCE

CC BY-NC-ND 4.0

REPOSITORY RECORD

Brewerton, Gary, and Jon Knight. 2019. "From Local Project to Open Source: A Brief History of the Loughborough Online Reading List System (LORLS)”. figshare. https://hdl.handle.net/2134/441. 


\section{Off theme}

From local project to open source: a brief history of the Loughborough Online Reading List System (LORLS)

\author{
Gary Brewerton and \\ fon Knight
}

The authors

Gary Brewerton and Jon Knight are based at the Pilkington Library, Loughborough University, Loughborough, UK. E-mail: g.p.brewerton@lboro.ac.uk and j.p.knight@lboro.ac.uk

\section{Keywords}

Reading lists, Databases, Library projects, University libraries

\section{Abstract}

Following a proposal at Loughborough University that "reading lists should be made available online" the university library undertook responsibility to design and develop a system to achieve this aim. Using open source tools the rapid development of a reading list management system soon followed, and by Autumn 2000 the solution had been successfully implemented at the university. The system is now available to other institutions as open source software.

\section{Electronic access}

The Emerald Research Register for this journal is available at http://www.emeraldinsight.com/researchregister

The current issue and full text archive of this journal is available at

http://www.emeraldinsight.com/0305-5728.htm

VINE: The Journal of Information and Knowledge Management Systems Volume $33 \cdot$ Number $4 \cdot 2003 \cdot$ pp. 189-195

(C) MCB UP Limited · ISSN 0305-5728

DOI $10.1108 / 03055720310510909$

\section{Background}

At Loughborough our first experiences of online reading lists came seven years ago with the introduction of a course-reading module as part of our then LMS (Library Management System). This allowed us to tag the bibliographic works in our database as being on a given course module, and allowed users to search by module title, module code or name of the academic and view a list of matching works. The service was released to users with little or no publicity and the only feedback we got was from students who wanted browseable lists of academics and module names rather than have to remember the name to enter in the search prompts; we did some local development of the library catalogue to achieve this.

In February 1999 the University's Learning and Teaching Committee approached the library with a view to developing a better service for all. An evaluation of the existing system was carried out and the following limitations were highlighted:

- only material held by the library was

listed;

- it did not show the academic's annotations: either for the list in general or against individual works;

- works on a list could only be listed alphabetically; and

- only a minority of lists were held.

Both the committee and the library were very keen that these problems should be addressed. The latter problem was of particular concern to the library as only a minority of academics ever sent their reading lists to the library. With access to all the academic's reading lists the library would be better able to manage its stock (e.g. acquisition of new material, putting items into the short loan collection) to support the teaching needs of the taught course students.

It was decided to set up a project to develop an online reading list system involving the library, the university's administrative computing unit and representatives from the Learning and Teaching Committee. What was fundamentally required was an electronic representation of the academic's paper-based reading list (and not just a list of library material 
which happened to be on a reading list). Just prior to the start of the project we were approached by our then LMS supplier to work with them on enhancing their existing system but we declined because first, we we were reluctant to consider another project partner at this late stage of the project; second, we had a short timescale (six months) to get a pilot service up and running, and had concerns about the supplier's speed of developments, and third, knew we would be going out to tender for a new LMS shortly and so did not want to base any new service on a system that might be replaced.

\section{Design and development}

Our first design consideration was how to store all the information on a reading list. The LMS held most of the bibliographic material but not all and library staff were reluctant to catalogue non-stock materials (e.g. departmental handbooks, material only held by the academic, etc.) just so they would appear on a reading list. Also there can be a lot of non-bibliographic information on a reading list, for example: references to websites or other online resources, commentary on the cited material and reading instructions from the academic. Even the structure of the reading list can hold important information, for example it can be ranked according to relevance or by subject category.

All of this pointed to the need for a separate database to hold the various elements of the reading lists. This had the added benefit of allowing us to cite material differently on the reading lists than on the Library catalogue. At Loughborough it is cataloguing practice to only site the main (or first) author of a work and to only capitalise the first word and any names in the title of the work. In the past there had been complaints from Loughborough academics where they had co-authored a work and their name was not listed or where the title of the work wasn't in exactly the same format as on the dust jacket.

The administrative computing unit undertook the initial development of the new reading list system with limited input from the library. By summer 1999 they had produced a prototype system using Oracle (relational database system) that addressed the limitations of the previous service but required the installation of proprietary software on any machine used to update the reading lists. The software was loaded onto a bank of PCs in the library and clerical staff from the Science Faculty were invited along to test the system.

A couple of significant problems were found with the prototype design: the use of proprietary software limited access to the service, it was possible for anyone with access to the service to (accidentally) change anyone else's reading list, and it was difficult for library staff to know when a reading list had been changed. Some academic departments also expressed concern over the manpower needed to input all their reading lists into the system. It was suggested that since many of the academics already had their reading lists available electronically (usually in Microsoft Word) it should be possible to simply import these into the system. A quick survey of the reading lists made available to the library showed that this would be impractical as a wide variety of formats and styles had been employed by the academics to produce their lists.

Another issue raised was that of intellectual property rights. Academic staff were concerned that if their reading lists were made easily available then it might be possible for other institutions to construct courses based upon them. While to an extent we shared their concerns we also did not what to put barriers between the students and the system so we reached a compromise: on campus use of the use of the system would be unrestricted but access from off campus would require a username and password.

As we began to consider these problems the administrative computing unit informed us that they were unable to commit any further resources to the project as they had other higher priority projects. We took this as an opportunity to re-evaluate the project requirements and also to ask the university for limited funds to support the project. Our first decision was to reject the proprietary software for the staff interface and recommend a Web-based interface; this implied a move from the large institutional based Oracle 
systems to a smaller locally hosted database system. To keep project costs down we suggested the use of open source software. The university approved the revised proposal and money was made available both to buy a PC to host the service and to hire temporary staff to re-key existing reading lists into the new system.

This meant that in March 2000 the Library's Systems Team took over responsibility for developing the system. A standard desktop PC was purchased and loaded with the Linux operating system. Included with the Linux distribution was MySQL, an open source relational database, which we had heard great things about and were keen to try out.

Our first concern was data entry. We wanted the system to be able to store bibliographic details for books, serials, articles and also websites. We considered using different entry forms for each type of resource but decided against it, as this would be a barrier to temporary staff or others who would not know or understand the resources and were simply re-keying existing reading lists into the system. So a three-part form was designed to allow for all the required bibliographic data and also any comments or recommendations that the academic may include (see Figure 1).

Next we looked into who should be able to edit the reading lists. Obviously the academics, and anyone working on their behalf, would need to be able to edit their own reading lists but also library staff would need access to potentially all the lists. We decided that whoever created the reading list in the first place on the system would have edit rights to it, and they in turn would be able to grant these rights to others. We considered giving library staff direct access to all the reading lists but because most library staff would only need to access a sub-set of the available reading lists we choose instead to simply give them the facility to add themselves as an editor to any list on the system. As for authentication we decided that instead of reinventing the wheel and creating our own authentication mechanism we would use that of the Web server (in our case Apache), authenticating over SSL against standard university passwords that academics already had.
In April the PC we had ordered to act as our server arrived. This was a standard desktop style Pentium with $128 \mathrm{Mb}$ RAM and $6 \mathrm{~Gb}$ disk. After loading RedHat 5.2 version of Linux (which included the Apache Web server, programming language Perl and of course MySQL) we started coding the system. Over the next two and a half months we produced an editing tool that allowed users to create new reading lists and to add, revise and delete both citations and notes to the list (see Figure 2).

Our final step in the initial development process was to test the system. We had already made arrangements to employ temporary staff over the summer to key in reading lists to the system and so took the opportunity to use one of these individuals as our guinea pig. After a week of inputting numerous reading lists from different academic departments, with differing styles, sizes and content we were confident of the ease of use of the interface and the correctness of the systems functionality.

\section{Implementation at Loughborough}

We started asking academic staff to submit their reading lists to the library, to be input into the new system, in May of 2000. Again in early July we reminded them to send us their reading lists and made a commitment to guarantee that all reading lists received by the end of August would be entered into the system and accessible by the start of the next academic session in October. As the reading lists arrived at the library, the library assistants would check for new materials to order, ready for the new academic year, and annotate the reading list with any details which might be missing (e.g. ISBN, ISSN, publisher, etc.) before they were passed to the temporary staff doing the data entry. We employed six temporary staff (mostly students looking for work over the summer) all spending half their day re-keying reading lists into the system and the other half of their time doing other work around the library. And by the end of the summer we had entered 857 reading lists into the system (see Figure 3).

When the students returned to

Loughborough for the start of the new 
Figure 1 Screen shot of draft input form

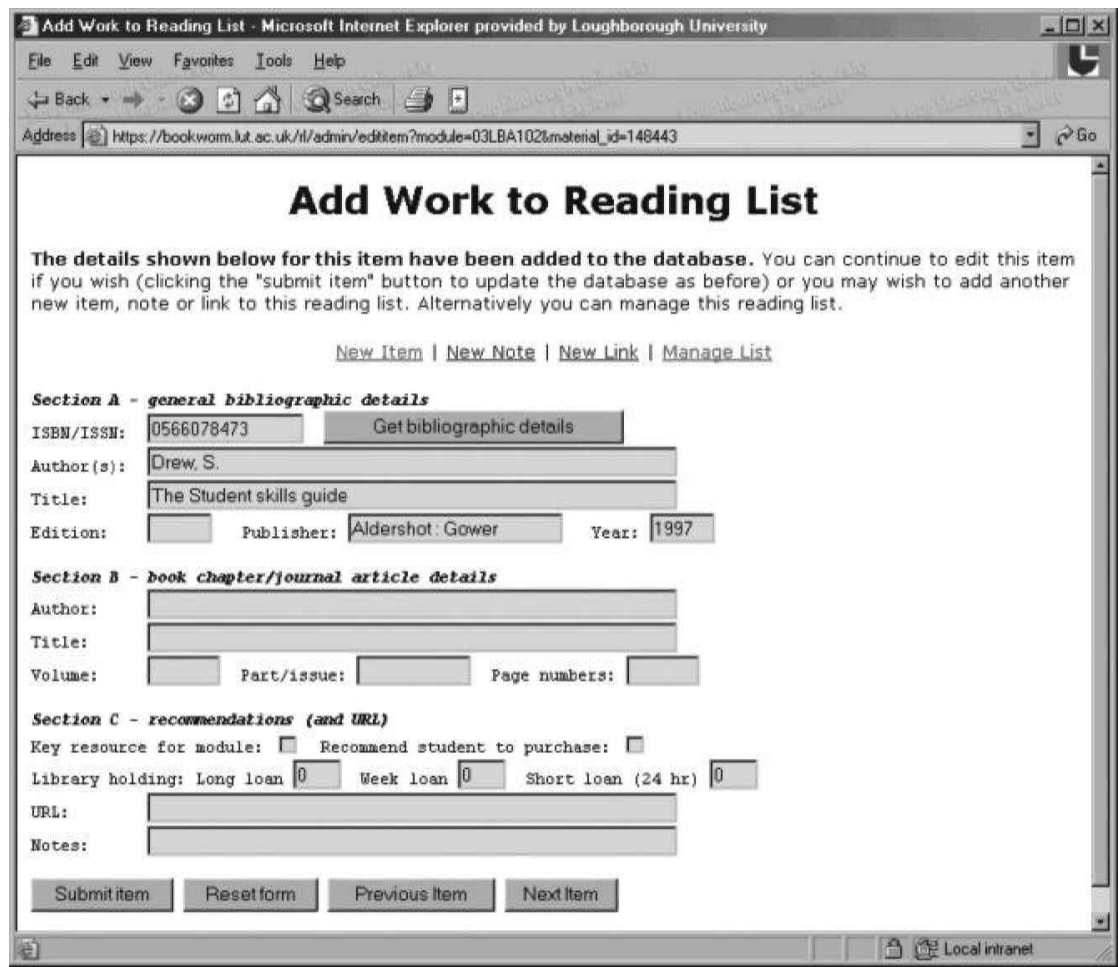

Figure 2 Screen shot of manage list

\begin{tabular}{|c|c|c|c|c|}
\hline \multicolumn{4}{|c|}{ EReading List Management - Microsolt Intenet Explorer provided by Loughbrough Univer ity } & 미조 \\
\hline \multicolumn{5}{|c|}{ Ele Edit Yiew Favontes Iools Heb } \\
\hline \multicolumn{5}{|c|}{ 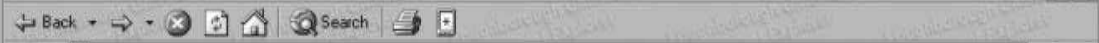 } \\
\hline \multicolumn{3}{|c|}{ 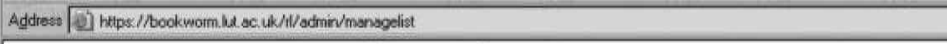 } & & Gio \\
\hline \multirow{4}{*}{\multicolumn{5}{|c|}{$\begin{array}{l}\text { Reading List Management } \\
\text { O3LBA102 - Bibliography for Finding information for your first } \\
\text { assignments } \\
\text { Ruth Stubbings } \\
\text { This form allows you to add, edit and delete items, notes and links in your reading list and also reorder them. To } \\
\text { edit or delete an item, note or link click on the edit or delete button next to the entry. To rearder an item, note } \\
\text { or link in your reading list enter the new position in the input box next to the entry and press the reorder button. } \\
\text { Alternatively you can add a new item, note or link to the end of your reading list. The owners and module name } \\
\text { of this reading list can be changed. }\end{array}$}} \\
\hline & & & & \\
\hline & & & & \\
\hline & & & & \\
\hline \multicolumn{5}{|c|}{ New Item I New Note | New Link | Edit Name \& Owners | Qther Lists | Create New List I Don't Publish | } \\
\hline \multicolumn{5}{|c|}{ Your reading list is currently: } \\
\hline \multicolumn{2}{|c|}{ Delete selected } & \multirow{2}{*}{\multicolumn{3}{|c|}{ ᄃ Alphabetically. Select everything I Select nothing }} \\
\hline \multicolumn{2}{|c|}{ Append selected to module: } & lected to module: & & \\
\hline Select & Rank & Entry & Editing & \\
\hline ᄃ & & $\begin{array}{l}\text { The Library has many books on study skills, I advise you carry out a keyword } \\
\text { search on OPAC to discover what is avalable, as well as looking at the items listed } \\
\text { below. }\end{array}$ & Edit note & \\
\hline ๘ & 2 & Drew, S., The Student skills guide, (1997), Aldershot: Gower [Held by Libraryl & Ecit item & \\
\hline$\square$ & & $\begin{array}{l}\text { Chpater } 4 \text { in Mastering study skills by Freeman, R., 2nd Edition, (1991), } \\
\text { Basingstoke : Macmillan Education Held by Libraryl }\end{array}$ & Edititem & \\
\hline
\end{tabular}


academic year in October the online reading lists system was live and accessible to them. Links were made from the Library Catalogue (OPAC) and at the bottom of the module specification page for each of the programme modules that was running in 2000 . There was little reaction from the students to the new system, most simply got on and used it, but what comments we did receive were all very positive.

The next step was to introduce the academic departments to the system. Many of the Subject Librarians took this as an opportunity to forge or strengthen their links with the academic departments. From November we allowed academics and departmental clerical staff to update the reading lists on the system, and at this time we also ran a series of training session on the system. The sessions usually lasted about two hours and allowed for hands-on practice with the system. The sessions were well attended and the response to the system was generally very positive, with any criticisms raised being constructive.

With academic now starting to update their own reading lists it was critical for the library to be alerted to any changes so that new or additional material could be ordered and items placed in the short loan collection (course reserves) to make the most effective use of the existing stock. We did this by first creating a report, restricted to the library staff, that showed all the changes made to a reading list since a given date, then creating an overnight batch job which emailed the relevant library staff with a summary of any reading lists that had been altered during that day.

We re-ran the training sessions both in early 2001, for the start of the second semester in February, and also throughout the summer of 2001 in preparation for the start of the next academic year. In most cases this was the first time that academic staff had been required to touch the system as their 2000-2001 reading lists had been done by the temporary staff employed the previous year. A few academic departments decided that the updating of the reading lists would be carried out by departmental clerical staff although most departments, including one that loudly proclaimed itself as being luddite, required that the academic staff responsible do the updating

Figure 3 Screen shot of display list

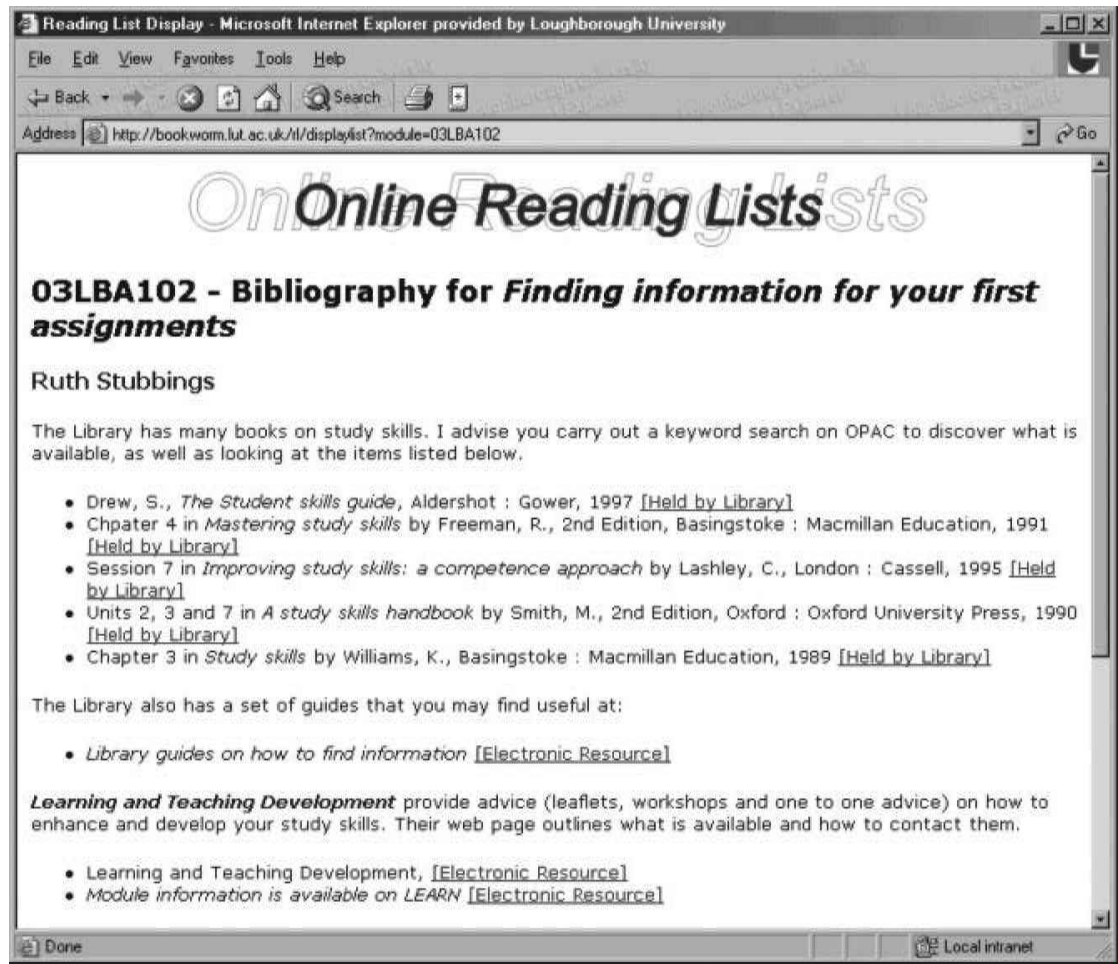


themselves (a position that the library wholeheartedly endorsed). The ease with which most academics took to the system can hopefully be attributed to both the ease-of-use of the system and the work done by our Subject Librarians in supporting it.

We did encounter some problems with departments that had not attended the training or that were already doing their own thing. Loughborough University has had it's own in-house VLE (virtual learning environment) for many years and some of the academic staff had already started to make their reading list available via it and did not see why they should get involved in "the library's system". An open meeting was held in December 2001 with those departments who had expressed concerns and we took this as an opportunity to specify additional requirements for the system, these included the ability to mark multiple items for deletion (at the time the system only allowed one item to be deleted at a time), some navigation improvements and the ability for users to display the reading lists without extraneous headers, footers or hypertext links in a more "printer friendly" format. Further development of the system was carried out in the first quarter of 2002 to meet these requirements.

During this period of implementing the reading list system, the library also was in the process of implementing a new LMS. Luckily because we had developed our system as an independent system to stand along side the LMS rather than be based upon it this did not cause many problems. We had to change the syntax to link to the relevant part of the catalogue (OPAC), and also the mechanism to retrieve bibliographic data from the library system. The latter meant a move over from harvesting data via a Web search to initially using Oracle client software and eventually the adoption of Z39.50 to query and retrieve data between our system and the LMS.

\section{Releasing the software to others}

In March 2002 we were visited by library staff from the University of Nottingham who were interested in comparing the functionality of our in-house system with that of their LMS. During the early development of the system we had considered making our software available as open source but never got round to doing it. With interest in the software from Nottingham we sought permission from the university to make the software available under GNU's General Public License, and after a short delay this was agreed to and the software was made available for downloading in May. The issue of selling the software was raised, but because we are not in a position to provide direct support for the system, and we had developed the system using open source resources so felt this was not appropriate, this was dismissed.

This first release of the open source code was not without its flaws and Nottingham encountered a number of problems with the installation, which they overcame. Taking into account their feedback from this experience we made adjustments to the software to make it more generic, removing a number of local restrictions or shortcuts, and also provided an installation script. We released version 2 of the software in late November of 2002 and publicised the software via appropriate mailing lists and Web sites in December.

Since then some 55 organisations have downloaded the open source from our Web site. The vast majority of these organisations being academic institutions throughout the UK but also some academic institutions from Europe, the USA, Canada, and Australia, and also a couple of LMS suppliers. The feedback we have received has been very interesting, with suggestions for new features, requests to visit us to learn more about the system, and even a couple of bug fixes. The University of Nottingham have recently gone live with a reading lists service based on our software and two other (academic) institutions have stated their intention to base new services on it.

We did encounter one unexpected problem with going open source, what is the software/system called? Developed as a local project a Loughborough we never needed to give it a name, we just referred to it as the "online reading list system", and those institutions that downloaded the software just tended to refer to it as "the Loughborough system".

However in an independent review of the system its name was quoted as being that of the server it is running on at Loughborough (i.e. Bookworm) because the reviewer found the 
name, or lack of one, "confusing when

continuously repeated in the report". As far as we are concerned the system is/was called the Loughborough Online Reading Lists System but because it is quite a mouthful to say repeatedly, and takes effort to write, so we have started referring to it using the acronym LORLS.

\section{Conclusion}

Working on this project has been a very rewarding experience. We now have a system at Loughborough that meets our current needs and may also answer those of other institutions.
And even where there is a reluctance to implement open source solutions, because of the need for local technical support rather than support from a supplier, the system can still be a source of inspiration; one reason we choose to release our software was to prove what can be done, both to academic institutions and to Library system suppliers. Our only big mistake during the whole process has been in not publishing anything about our efforts, either during the initial development, the implementation here, or with the release of the open source. Hopefully one day we will get round to writing a paper and maybe even getting it published. 